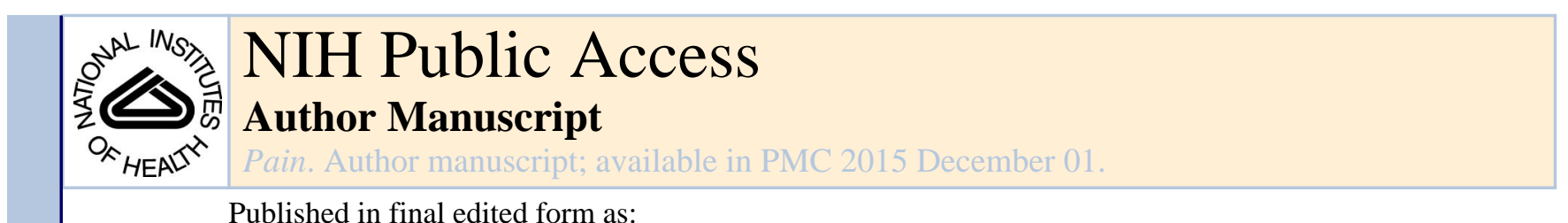

Published in final edited form as:

Pain. 2014 December ; 155(12): 2662-2672. doi:10.1016/j.pain.2014.09.033.

\title{
TRPV4 is necessary for trigeminal irritant pain and functions as a cellular formalin receptor
}

\author{
Yong Chen ${ }^{\mathrm{a}}$, Patrick Kanju ${ }^{\mathrm{a}, \uparrow}$, Quan Fang ${ }^{\mathrm{a}, \uparrow}$, Suk Hee Lee ${ }^{\mathrm{a}}$, Puja K. Parekh ${ }^{\mathrm{a}}$, Whasil Lee ${ }^{\mathrm{a}}$, \\ Carlene Moore $^{\mathrm{a}}$, Daniel Brenner ${ }^{\mathrm{b}}$, Robert W. Gereau IV ${ }^{\mathrm{b}}$, Fan Wang ${ }^{\mathrm{c}}$, and Wolfgang \\ Liedtke $\mathrm{a}^{\mathrm{a}, \mathrm{c}, \mathrm{d}, \mathrm{e},{ }^{*}}$ \\ aDeptment of Neurology, Duke University, Durham, NC 27710 \\ bPain Center and Department of Anesthesiology, Washington University, St. Louis, MO 63110 \\ 'Deptment of Neurobiology, Duke University, Durham, NC 27710 \\ dDeptment of Anesthesiology, Duke University, Durham, NC 27710 \\ ${ }^{e}$ Clinics for Pain and Palliative Care, Duke University, Durham, NC 27710
}

\begin{abstract}
Detection of external irritants by head nociceptor neurons has deep evolutionary roots. Irritantinduced aversive behavior is a popular pain model in laboratory animals. It is used widely in the formalin-model, where formaldehyde is injected into the rodent paw, eliciting quantifiable nocifensive behavior that has a direct, tissue-injury-evoked phase, and a subsequent tonic phase caused by neural maladaptation. The formalin model has elucidated many anti-pain compounds and pain-modulating signaling pathways. We have adopted this model to trigeminally-innervated territories in mice. Also, we have examined the involvement of TRPV4 channels in formalinevoked trigeminal pain behavior, because TRPV4 is abundantly expressed in trigeminal ganglion (TG) sensory neurons, also because we have recently defined TRPV4's role in response to airborne irritants, and in a model for temporomandibular joint pain.

We found TRPV4 to be important for trigeminal nocifensive behavior evoked by formalin

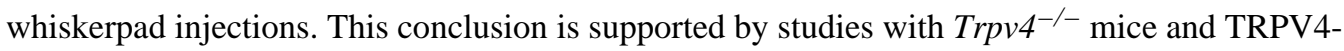
specific antagonists. Our results imply TRPV4 in MEK-ERK activation in TG sensory neurons. Furthermore, cellular studies in primary TG neurons and in heterologous TRPV4-expressing cells suggest that TRPV4 can be activated directly by formalin to gate $\mathrm{Ca}^{++}$. Using TRPA1-blocker and
\end{abstract}

(C) 2014 The Authors. Published by Elsevier B.V. on behalf of International Association for the Study of Pain.

*Corresponding author: Dr. Wolfgang Liedtke, Department of Neurology; Duke Clinics for Pain and Palliative Care, Duke University Medical Center, Durham, NC 27710, USA, wolfgang@neuro.duke.edu, Tel.: +1-919-684 0058, Fax: +1-919-684 6514.

Ithese authors contributed equally

Author contributions:

Y.C., R.W.G., F.W., and W.L. designed research; Y.C., Q.F., P.K., S.H.L., P.K.P., W.L., and C.M., performed research; D.B. and R.W.G. contributed new reagents/analytic tools; Y.C., P.K., S.H.L., and W.L. analyzed data; and Y.C., R.W.G., F.W., and W.L. wrote the paper.

None of the authors have conflicts of interest with respect to this work.

Publisher's Disclaimer: This is a PDF file of an unedited manuscript that has been accepted for publication. As a service to our customers we are providing this early version of the manuscript. The manuscript will undergo copyediting, typesetting, and review of the resulting proof before it is published in its final citable form. Please note that during the production process errors may be discovered which could affect the content, and all legal disclaimers that apply to the journal pertain. 
Trpal $^{-/-}$mice, we found that both TRP channels co-contribute to the formalin trigeminal pain response.

These results imply TRPV4 as an important signaling molecule in irritation-evoked trigeminal pain. TRPV4-antagonistic therapies can therefore be envisioned as novel analgesics, possibly for specific targeting of trigeminal pain disorders, such as migraine, headaches, TMJ, facial and dental pain, and irritation of trigeminally-innervated surface epithelia.

\section{Introduction}

The trigeminal sensory system enables vertebrate animals to detect a wide range of environmental stimuli, including noxious cues such as chemical irritants. Detection of environmental irritants by the trigeminal system subserves a sentinel function that has enhanced evolutionary fitness of the respective species. Although some progress has been made, the molecules that sense the chemical irritants, and signal the noxious cue in the trigeminal system remain largely elusive.

Formalin is a prototypical irritant which has been formulated in aqueous solution so that it can be injected into tissue. In the study of pain, the formalin model has led to profound insights on analgesic potency of candidate drugs and to elucidation of signaling pathways related to pain $[9 ; 14 ; 17 ; 32 ; 34 ; 35]$. Formalin is an electrophile and reacts with a variety of amino acids by nucleophilic addition. It also irreversibly crosslinks proteins. These chemical properties of formalin have been viewed as contributory to tissue injury. Via these mechanisms, formalin can also directly irritate nerve terminals of nociceptor neurons. Together, these events are viewed as causal for pain behavior following formalin injection. Whether there are specific protein targets that are critical for formalin-evoked pain and their eventual identity is largely unknown. However, TRPA1 channels have been implicated as critical regulators of the formalin behavioral response and also in response to formalin and other electrophilic irritants in heterologous cellular systems [23; 24]. This raises the question whether other molecules, in particular another TRP ion channel could be playing any role in response to formalin.

Practically, extra-trigeminal somatosensory exposure to formalin in humans virtually does not occur as a pain-eliciting or -facilitating condition [38], yet airborne trigeminal exposures facilitate headaches and local painful irritations of conjunctivae of the eyes, sinuses and upper airways [25;29]. However, the vast majority of reported applications of the formalin model is extra-trigeminal, with formalin injection to the hindpaw. Therefore, one of our main rationales was to adapt the formalin model to trigeminally-innervated areas [5; 22], using mice. In terms of which mouse line to subject to trigeminal formalin injections, we decided to use Trpv $4^{-/}$mice, so that the role of TRPV4 in trigeminal irritant pain could be assessed, based on our previous findings that TRPV4 was critical for airborne irritation in upper airways [19] and a key contributor to temporomandibular joint pain induced by arthritogenic irritant [8].

Our results demonstrate an essential role for TRPV4 in the trigeminal formalin response invivo, TRPV4 activation by formalin in TG sensory neurons and in heterologous cellular 
systems. Our findings reiterate the concept that TRPV4 forms a relevant target in trigeminal pain via its expression in TG sensory neurons.

\section{Materials and Methods}

\subsection{Animals}

The pan-null phenotype of $\operatorname{Trpv} 4^{-/-}$mice relies on excision of the exon encoding transmembrane domains 5-6. Mice were outcrossed to C57BL/6J background and PCRgenotyped [21]. Trpal $^{-/-}$mice (B6;129P-Trpal ${ }^{\text {tml } 1 \mathrm{Kykw} / \mathrm{J})}$ were from the laboratories of Drs. Robert W. Gereau (Washington University) and Ru-rong Ji (Duke University). Male WT (C57BL/6J), Trpv4 $4^{-/}$, and Trpa1 ${ }^{-/-}$mice, 2-2.5 months of age, were used for all experiments.

Epidermal-specific, Tamoxifen (tam)-inducible Trpv4 knockdown mice were created as previously described [26]. In brief, the Trpv4 genomic locus was engineered so that loxP sites surrounded exon 13, which encodes TM5-6. This mutation was propagated in mice that were crossed to K14-CRE-ER ${ }^{\text {tam }}$ mice, so that ((Trpv $\left.\left.4^{\text {lox/lox }}\right) \mathrm{X}\left(\mathrm{K} 14-\mathrm{CRE}-\mathrm{ER}^{\mathrm{tam}}\right)\right)$ mice could be induced by tam administration via oral gavage for five consecutive days at 6 $\mathrm{mg}$ /day in $0.3 \mathrm{~mL}$ corn oil, at age 2-2.5 months of age, plus a one-time booster 2 weeks after the last application. Control animals received the same volume of corn oil. Efficiency of targeting was verified by qRT-PCR and immunohistochemistry for Trpv 4 expression in skin at gene and protein level respectively [26].

Male dominant-negative mitogen-activated protein kinase kinase (dnMEK) transgenic mice, 2-2.5 months of age, were used. The neuron-specific and pan-neuronal Ta1 a-tubulin promoter was used to drive the transgene [31]. We documented expression of dnMEK in TG sensory neurons [8].

Animals were housed in climate-controlled rooms on a 12/12h light/dark cycle with water and standardized rodent diet available ad libitum. All animal protocols were approved by the Duke University IACUC in compliance with NIH guidelines.

\subsection{Formalin-induced pain behavior and chemical injections}

Mice were allowed to acclimate to a Plexiglas chamber for at least 30 min before testing, and received $10 \mu \mathrm{L}$ subcutaneous injection of $4 \%$ of formalin (diluted from an aqueous solution of commercial $37 \%$ formaldehyde with normal saline (NS)) through a 30-gauge needle or saline into the right whiskerpad or into the right hindpaw [22]. After injection, mice were immediately placed back in chamber and the rubbing behavior was recorded by a Panasonic videocamera for a $45 \mathrm{~min}$ observation period. The recording time was divided into 9 blocks of $5 \mathrm{~min}$, and a nociceptive score was determined per block by measuring the time that the animals spent rubbing the injected area predominantly with the ipsilateral forepaw and rarely with hindpaw for whiskerpad injection, and the time spent licking, flicking and lifting the injected hindpaw. The rubbing behavior with forepaw is evoked by pain, which is distinct from itch behavior [33]. Behavioral analysis was conducted by observers blinded to genotype. 
To investigate the effects of the specific TRPV4 inhibitor HC067047 or GSK205 on formalin-induced nociceptive behavior, mice received a single intraperitoneal (i.p.) administration of HC067047 (dissolved in 6\% DMSO; Sigma) or received a single subcutaneous injection of GSK205 into the whiskerpad (10 $\mu \mathrm{L}$, dissolved in 4\% DMSO) 15 min before formalin injection. For testing the effect of $4 \mathrm{a}-\mathrm{PDD}(10 \mu \mathrm{L}$, dissolved in $4 \%$ DMSO), a specific agonist of TRPV4, on pain behavior, mice received a subcutaneous injection into the whiskerpad. In addition, to investigate the effects of the specific MEK inhibitor U0126 on formalin-induced nociceptive behavior, mice received a single subcutaneous injection of U0126 into the whiskerpad $(10 \mu \mathrm{L}$, dissolved in $20 \%$ DMSO) 15 min before formalin injection. Control animals received the same volume of NS, $4 \%, 6 \%$ or $20 \%$ of DMSO.

\subsection{Immunohistochemistry, morphometry analysis and neural tracing}

Routine procedures were followed [8]. Briefly, mice were perfused transcardially with $0.01 \mathrm{M}$ phosphate buffered saline (PBS) followed by ice-cold $4 \%$ paraformaldehyde (PFA) at the experimental time-point under study. Their TGs and whiskerpad skin were dissected and post-fixed in $4 \%$ PFA overnight, cryoprotected in $20 \%$ sucrose (48 h) and sectioned on a cryostat at $12 \mu \mathrm{m}$ and $20 \mu \mathrm{m}$ respectively. Sections were blocked with $5 \%$ normal goat serum (Jackson), and incubated overnight with primary antibodies: rabbit anti-TRPV4 (1:300, Abcam), mouse anti-Keratin 14 (1:200, Santa Cruz), guinea pig anti-PGP 9.5 (1:500, Neuromics), rabbit anti-phospho-ERK (pERK, 1:250, Cell Signaling Technology), and mouse anti-pERK (1:600, Cell Signaling Technology; for double-labeling with TRPV4 in TG). Immunodetection was accomplished with secondary antibodies (AlexaFluor 594conjugated goat anti-rabbit; AlexaFluor 488-conjugated goat anti-mouse or -guinea pig; all 1:500; Invitrogen) for $2 \mathrm{~h}$, and cover-slipped with Vectashield (Vector). Digital micrographs were acquired using a BX61 Olympus upright microscope equipped with high-resolution CCD camera and with constant acquisition/exposure settings, using ISEE software (ISEE Imaging Systems, Raleigh NC).

To track whiskerpad skin innervation of TRPV4 and/or pERK expressing TG neurons, mice were injected with $1.5 \mu \mathrm{L}$ of neural tracer Fast-Blue (FB, $2 \%$ aqueous solution,

Polysciences) into whiskerpad 2 days before NS or $4 \%$ formalin administration. 5 min after the last injection, mice were perfused, and tissues were immunostained as described above.

For every animal under study, 4-6 TG sections were analyzed per mouse; neurons were identified by morphology. The cutoff density threshold was determined by averaging the density of three neurons per section that were judged to be minimally positive, using ImageJ software. All neurons for which the mean density exceeded the threshold $>25 \%$ were judged as positive. Positive cells were expressed as \% of total counted TG neurons.

\subsection{Western blot}

Routine procedures were followed [8]. Briefly, snap-frozen TGs and whiskerpad skin were protein-extracted in CHAPS, and electroblotted to nitrocellulose membranes after gel separation of proteins in a $10 \%$ polyacrylamide gel. Membranes were blocked with 5\% drymilk, pERK and ERK were specifically detected with primary antibodies (rabbit anti-pERK 
and anti-ERK, both at 1:500; Cell Signaling Technology), secondary antibody (anti-rabbit peroxidase-conjugated, 1:5000; Jackson ImmunoResearch) and chemoluminescence substrate (ECL-Advance, GE Healthcare). Abundance was quantified using ImagePro Plus software. $\beta$-actin, as a control, was detected with a mouse monoclonal anti- $\beta$-actin antibody (clone AC-5, 1:500; Abcam).

\subsection{Cell culture and $\mathrm{Ca}^{++}$imaging}

N2a cells were cultured on poly-D-lysine and laminin coated cover slips in a 24 well plate containing DMEM media (Sigma) supplemented with 10\% bovine serum and penicillin/ streptomycin. After 24h, cells were transfected with rTRPV4-GFP or GFP alone (control) using the lipofectamine 2000 protocol (Invitrogen).

TGs from 1.5-2 months old male WT and Trpv4 $4^{-/-}$mice were dissected and digested with 1 $\mathrm{mg} / \mathrm{mL}$ collagenase (Worthington, CSL1) and $5 \mathrm{mg} / \mathrm{mL}$ dispase (Invitrogen) for $45 \mathrm{~min}$, then triturated [6]. The resulting cell suspension was filtered through a $70 \mu \mathrm{m}$ cell strainer (BD Falcon) to remove debris. Neurons were cultured in DH10 medium (1:1 DMEM:HamsF12, Invitrogen) with $10 \%$ fetal bovine serum (Sigma), $100 \mathrm{U} / \mathrm{mL}$ penicillin and $100 \mu \mathrm{g} / \mathrm{mL}$ streptomycin (Gibco) and $50 \mathrm{ng} / \mathrm{mL}$ nerve growth factor (NGF; USBiological) on coverslips coated with poly-D-lysine and laminin (Invitrogen), and incubated with $5 \% \mathrm{CO}_{2}$ at $37^{\circ} \mathrm{C}$. $\mathrm{Ca}^{++}$imaging was performed next day after culture. Primary mouse keratinocytes were cultured as previously described [26]. The epidermis from back skin of newborn WT mice was separated from the dermis by a $1 \mathrm{~h}$ dispase (BD Biosciences) treatment. Then the keratinocytes were dissociated from the epidermis using trypsin (Gibco). Keratinocytes were plated on collagen-coated dishes or glass coverslips and grown in keratinocyte serum-free media (Gibco) supplemented with bovine pituitary extract and epidermal growth factor (EGF; R\&D Systems), 100 pmol cholera toxin (Calbiochem), and 1x antibiotics/ antimycotics (Gibco) in an incubator at $5 \% \mathrm{CO}_{2}$ and $37{ }^{\circ} \mathrm{C}$.

$\mathrm{Ca}^{++}$imaging of primary TG neurons and epidermal keratinocytes in response to formalin was conducted after loading with $2 \mu \mathrm{M}$ fura2-AM (Invitrogen) for 30min, following a ratiometric $\mathrm{Ca}^{++}$-imaging protocol with $340 / 380 \mathrm{~nm}$ blue light for dual excitation [26]. Ratios of emissions were acquired at $0.5 \mathrm{~Hz} . \Delta \mathrm{R} / \mathrm{R}_{0}$ was determined as the fraction of the increase of a given ratio over baseline ratio, divided by baseline ratio. To investigate the effects of the specific TRPV4 inhibitor GSK205 [26; 28] or TRPA1 inhibitor A-967079 [7; 30] on formalin-induced $\mathrm{Ca}^{++}$influx, cells were incubated with GSK205 or A-967079 15 min before formalin stimulation.

\subsection{Electrophysiology}

Heterologously transfected N2a cells were recorded as described previously [19]. Patch clamp recordings were performed $24 \mathrm{hrs}$ after transfection. Briefly, cultured cells on individual cover slips were incubated for $10 \mathrm{~min}$ at $37^{\circ} \mathrm{C}$ in extracellular solution containing (mM) $1 \mathrm{MgCl}_{2}, 10$ Glucose, 10 HEPES, $145 \mathrm{NaCl}$ and $2 \mathrm{CaCl}_{2}$ (pH 7.4, 310mOsM). Cells were then transferred to a recording chamber staged on an inverted Leica microscope that was equipped with fluorescent filters. Each GFP labeled cell was identified for whole cell currents recording using a glass electrode. The glass electrodes were pulled (P-80/PC; Sutter 
Instruments) from borosilicate glass capillaries (Warner Instruments) and had resistances of 2.5-3.0 mega-ohm. Before recording, the glass electrodes were filled with intracellular solution containing (mM) $140 \mathrm{CsCl}$, 10 HEPES, 1 EGTA, $0.3 \mathrm{Na}$-GTP, 2 Na2-ATP, and 2 $\mathrm{MgCl}_{2}$ (pH 7.4, 295mOsM). Whole cell currents were recorded using pclamp 9 software (molecular Devices CA) and Axopatch 200B amplifier (Axon Instruments, CA). The cell was first clamped at $-65 \mathrm{mV}$ in voltage clamp mode, and a $1 \mathrm{sec}$ voltage ramp from $-110 \mathrm{mV}$ to $+120 \mathrm{mV}$ was applied every 2 seconds for $15-20$ sweeps.

Formalin was only added after a stable baseline was established. For recording the effect of

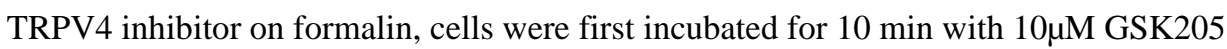
before adding formalin. The recorded data were filtered at $2 \mathrm{kHz}$ and digitized at $10 \mathrm{kHz}$. The capacitance was monitored during recording and any data with $\mathrm{a} \pm 5 \mathrm{pF}$ change were excluded from analysis. Post recoding analysis was conducted using clampfit 9 software.

\subsection{Statistical analysis}

All data are expressed as mean \pm SEM. Two-tail $t$-tests or one-way ANOVA followed by Tukey post-hoc test were used for group comparison. $P<0.05$ indicated statistically significant differences.

\section{Results}

\subsection{Trpv4 in TG sensory neurons is essential for formalin evoked irritant pain}

Subcutaneous injections of minute amounts of diluted formalin elicit an acute response that lasts approximately 5 minutes directly after injection. An intermediary phase is characterized by less pain behavior for the next 10 minutes [11]. This is followed by a tonic or late response for the next 30-45 minutes with again increased nocifensive behavior, which is sustained by maladaptive neural responses, demonstrated for sensory relay neurons in the spinal cord dorsal horn [40].

In laboratory mice of a C57BL/6J genetic background, we found a biphasic response after whiskerpad injection of $10 \mu \mathrm{L}$ of $4 \%$ formalin (Fig. 1A). "Biphasic" has to take into account that the interphase did not equal lack of nocifensive behavior after saline injections, but was clearly less pronounced than acute or tonic phase. The acute phase was characterized by $1 / 2$ time spent with nocifensive behavior, the tonic phase by $1 / 3$ of the time (Fig. 1B). We selected $4 \%$ formalin in $10 \mu \mathrm{L}$ injection volume because this application can produce the most robust nocifensive behavior [22].

Having elaborated these basics of the irritant behavioral response to formalin in the trigeminal system, we next subjected $\operatorname{Tr} p v 4^{-/-}$pan-null mice to formalin injections, based on the rationales laid out above. We found significantly attenuated nocifensive behavior in these mice for all phases (Fig. 1C-D). This result indicates that Trpv4 is necessary for both, the acute response to tissue injury by formalin in the whiskerpad, and the protracted, tonic response, which is neurally mediated by the trigeminal system. In order to confirm and extend these findings, we pre-applied a TRPV4-selective inhibitor, HC067047 [10], by systemic application. We obtained similar results as for genetically-encoded deletion in $\operatorname{Trp} v 4^{-/-}$mice. In addition, attenuation of the tonic phase of the response was dose- 
dependent (Fig. 1E-F). Acute block of TRPV4 function that leads to a similar result as genetically-encoded gene deletion of Trpv4, indicates that TRPV4 channels contribute to the trigeminal formalin response as observed here, importantly without apparent contribution by genes that are up-regulated in a compensatory manner when deleting Trpv4. Based on the dose-dependent attenuation of the formalin response by systemic application of TRPV4inhibitor, HC067047, we also wanted to learn whether whiskerpad injection of a TRPV4 inhibitor had a similar effect or perhaps more pronounced impact on one specific response phase. We used the rapid-onset, rapid clearance TRPV4-selective blocker, GSK205 [19; 28; 41], which we used previously in a sunburn pain model where the compound proved effective upon topical application and devoid of off-target effects [26]. Surprisingly, the protracted tonic phase was attenuated more robustly, also in a clearly dose-dependent manner, by GSK205 than its effects on the acute and inter-phase (Fig. 1G-H). One reason for this effect could be the protracted diffusion to reach the compound's targets for the acute phase. However, differences in attenuation of the acute phase between different Trpv 4 lossof-function experiments were moderate.

Importantly, all three experiments share the feature that the protracted neural phase is regulated by TRPV4. The effect we noticed the most was the response to whiskerpad injection of GSK205. GSK205 off-target effects could not be seen in our trigeminal formalin model (Fig. 1H). This result, together with established insights on the tonic phase of the formalin model, and with known functional expression of TRPV4 channels in TG sensory neurons $[8 ; 20 ; 21]$, suggests that the critical site of action for TRPV4 in the trigeminal formalin response could be in TG sensory neurons. However, given the robust TRPV4 expression in epidermal keratinocytes [26], also see Fig. 5A-B), we also considered a cocontribution by epidermal TRPV4 to the formalin response, essentially for all three phases. We did not find evidence in favor of this hypothesis because we recorded identical abundance of nocifensive behavior in a Trpv 4 keratinocyte-specific, inducible knockout that we have developed previously [26]. Induced and sham-induced mice showed the same robust nocifensive behavior for all three phases (Fig. 1I-J). Thus, TRPV4 channel expression by TG sensory neurons, including their peripheral projections to the whiskerpad, appear key expression sites for the observed nocifensive response in all three phases. TRPV4 expression in keratinocytes plays no role, and rapid migration of other TRPV4expressing non-neural cells to the site of injection that subsequently regulate the tonic phase of the trigeminal formalin behavioral response appears unlikely and is not supported by current understanding of the formalin model. Therefore, TG sensory neurons are the most likely sites of TRPV4 function in response to whiskerpad injection of formalin. This conclusion is highly likely for the neurally-mediated, tonic phase. For the acute phase, a major contributory role of TRPV4 appears likely.

In order to conduct a gain-of-function study on the role of trigeminally-expressed TRPV4, we injected TRPV4-selective activators, 4a-PDD and GSK101 [4; 37], into the whiskerpad. This led to a monophasic behavior, reminiscent of the formalin acute phase, but more protracted, and lacking subsequent phases (Fig. 1K-L). GSK101 proved slightly more potent than 4a-PDD (data not shown). The elicited behavior was dependent on TRPV4, as shown by the greatly attenuated response of $\operatorname{Trpv} 4^{-1-}$ mice (Fig. 1K-L). However, there was 
also a minor effect in the null background, pointing towards a marginal off-target effect by $4 a-P D D$ as a trigeminal irritant. When using again the keratinocyte-specific and inducible Trpv4 knockdown mouse [26], there was identical nocifensive behavior in these animals when inducing Trpv4 knockdown, as compared to WT (Fig. 1K-L). These findings suggest that TRPV4 is needed for the nocifensive response to whiskerpad injections of a known TRPV4-selective activator, 4a-PDD, yet that TRPV4 expression in keratinocytes of the whiskerpad skin plays no role in this behavior.

Taken together, loss-of-function experiments on the role of TRPV4 in the trigeminal formalin response, and gain-of-function experiments on the role of TRPV4 in nocifensive behavior in response to whiskerpad injection of selective TRPV4 activators, both suggest that TRPV4 is an irritant receptor expressed by and functional in TG sensory neurons. Robust expression of TRPV4 by whiskerpad skin keratinocytes does not play a role in the nocifensive behavioral response to whiskerpad injections of formalin or selective chemical TRPV4-activators. Furthermore, we excluded an exclusive trigeminal role of TRPV4 in the trigeminal formalin response by eliciting a footpad formalin response and demonstrating similar Trpv4 dependence, using $\operatorname{Trp} v 4^{-/-}$mice (Suppl. Fig. 1).

\subsection{ERK signaling downstream of TRPV4 in TG sensory neurons is critical for formalin evoked irritant pain}

Based on our previous observations of MEK-ERK MAP-kinase signaling likely downstream of TRPV4 expressed in TG sensory neuron [8], also on related findings in sensory neurons and airway epithelial cells $[1 ; 19]$, we tested the trigeminal formalin response of mice with dominant-negative MEK expression directed to neurons, including TG sensory neurons [8]. We observed significantly reduced nocifensive behavior in response to whiskerpad injections of formalin in the interphase and tonic phase, not in the acute phase (Fig. 2A-B). This result suggests that MEK-ERK is likely functioning downstream of TRPV4 in TG sensory neurons in formalin-evoked nocifensive behavior, and that this mechanism is relevant for inter- and tonic phase of the formalin response. Dominant-negative MEK is also effective in central neurons that transmit pain [16], but this location as a cause of its effect in the trigeminal formalin response is less likely because of the following result. We complemented assessment of the dnMEK mouse with whiskerpad injections of specific MEK inhibitor, U0126 [15]. As a result, we observed significant attenuation of nocifensive behavior. This effect, for the tonic, neurally-mediated phase, was dependent on the dose of U0126 applied (Fig. 2C-D). The acute phase was sensitive to even the lowest dose of U0126. The acute phase therefore shows an interesting profile, namely it is Trpv4-dependent (Fig. 1), at the same time not MEK-ERK dependent in TG neurons (Fig. 2A-B), but robustly MEK-ERK dependent locally in the whiskerpad (Fig. 2C-D). These observations during the acute phase can be reconciled with TRPV4 functioning in non-neural cells up-stream of MEK-ERK, such as endothelial cells and macrophages, both of them known to express TRPV4 $[2 ; 12 ; 13 ; 27 ; 36]$. These cells participate in sensitizing peripheral nerve endings to formalin. Together, our results suggest that MEK-ERK signaling, downstream of TRPV4mediated $\mathrm{Ca}^{++}$signaling, functions as a significant mechanism in the organismal trigeminal formalin response. In keeping with this conclusion, we detected ERK phosphorylation in response to whiskerpad injection of formalin within 5 minutes post-injection, both in 
whiskerpad and TG extracts (Fig. 2E-G). The increased phosphorylation level was sustained in both tissues at the 45 minute time-point (Fig. 2E-G). Immuno-labeling studies in the TG demonstrated phosphorylated ERK to be strictly neuronal (Fig. 2H). We next asked whether this regulation did indeed depend on Trpv4. We uncovered affirmative results by use of Trpv $4^{-/-}$mice, systemic application of HC067047 and whiskerpad injections of GSK205. This was observed at both the 5 minute and 45 minute time-points, indicative of the rapid as well as sustained dynamics of the TRPV4-dependent regulation (Fig. 2H-I). Confirming the specificity of the approach, ERK phosphorylation in TG neurons was reduced in dnMEK transgenic mice and in mice with whiskerpad pre-injections of U0126, in response to whiskerpad injections of formalin (Fig. $2 \mathrm{H}$, J). These results validate the above conclusion of TRPV4 functioning upstream of MEK-ERK. Therefore, this signaling mechanism in TG sensory neurons likely underlies the tonic neural phase of the trigeminal formalin behavioral response.

\subsection{TRPV4 is activated by formalin in cultured heterologous cells and TG sensory neurons}

To complement and extend our in-vivo studies, we conducted experiments in dissociated TG sensory neurons and in heterologous cells with directed expression of TRPV4. For the latter, we observed a concentration-response relationship for formalin application, using $\mathrm{Ca}^{++}$ imaging as a readout in $\mathrm{N} 2 \mathrm{a}$ cells (Fig. $3 \mathrm{~A}, \mathrm{EC}_{50}=0.00638 \%$ formalin). A similar response was detected in TRPV4-expressing HEK293T cells (data not shown). Control-transfected N2a cells displayed a minimal response to formalin $(0.01 \%)$. The $\mathrm{Ca}^{++}$response to formalin

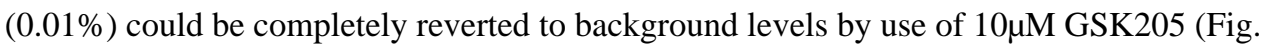

3B). We recapitulated this experiment using patch-clamp electrophysiology, where we noticed the typical outward rectification in TRPV4-expressing N2a cells that were stimulated with formalin. Channel activation was reverted to background levels in the

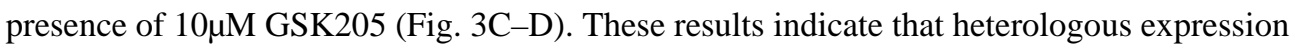
of TRPV4 channels is sufficient to confer upon a minimally-responsive cell robust responsiveness to dilute formalin. This response is mediated by TRPV4. TRPV4 is therefore an ionotropic formalin receptor, or it supplies the critical channel element to a signaling chain that is present in N2a and HEK293 cells.

We next investigated TG sensory neurons' response to formalin, using $\mathrm{Ca}^{++}$imaging. We observed an appreciable $\mathrm{Ca}^{++}$response to formalin $(0.01 \%)$ in $27.66 \%$ of the TG neurons (Table 1). This response rate was not different from that elicited by stimulation with $4 a-$ PDD $(5 \mu \mathrm{M})$. Indicative of a critical involvement of TRPV4, the response rate decreased to 9.7\% when applying GSK205 $(10 \mu \mathrm{M})$. In addition, for responsive cells, intracellular $\mathrm{Ca}^{++}$ evoked by formalin was reduced 50\% when directly antagonizing TRPV4 with GSK205 $(10 \mu \mathrm{M}$, pre-exposure for $15 \mathrm{~min})$. Genetically-encoded absence of Trpv4 led to a slightly increased response rate as in WT (32.12\% vs. $27.66 \%$, Table 1). Neurons from Trpv $4^{-/-}$ mice showed a formalin-evoked $\mathrm{Ca}^{++}$-response that was decreased by $50 \%$ in terms of intracellular concentration (Fig. 4A). When examining the formalin-response of dissociated keratinocytes, we found it to be independent of TRPV4, evidenced by its presence in keratinocytes derived from $\operatorname{Trp} v 4^{-1-}$ mice, and when applying GSK205, all together not different from that of WT mice (Fig. 4C). Of note, these cells do respond to specific chemical activation of TRPV4 by 4a-PDD and GSK101 [26]. Thus, TG sensory neurons do 
respond to formalin directly. This response is sustained by TRPV4 ion channels that these neurons express. Antagonism of TRPV4 channels reduced the number of formalinresponsive neurons and reduced the $\mathrm{Ca}^{++}$signal by $1 / 2$ in the remainder responsive neurons. Genetically-encoded absence of Trpv 4 attenuated the $\mathrm{Ca}^{++}$signal by $1 / 2$, not reducing the number of responsive cells, indicating gene-regulatory compensation in the $\operatorname{Trpv} 4^{-/-}$pannull mouse. These findings suggest a significant contribution of TRPV4 ion channels to the formalin response of TG sensory neurons, but also the presence of another formalinresponsive pathway. In the first place, the established formalin receptor, TRPA1 comes to mind as a candidate mechanism to underlie the non-TRPV4 related formalin-response [23; 24]. We began to explore this question by using the potent and specific TRPA1-inhibitory compound A-967079 [7;39] in our experiments. It led to an attenuated $\mathrm{Ca}^{++}$signal in WT TG neurons and a further reduction in $\operatorname{Trp} v 4^{-/-}$TG neurons in response to formalin (Fig. 4B). The percentage of responsive cells was reduced from $27.7 \%$ to $15.8 \%$ when acutely blocking TRPA1, and to a mere $3.2 \%$ in Trpv $4^{-/-}$TG neurons plus TRPA1 inhibitor (Table 1). Thus, TRPV4 and TRPA1 appear to co-contribute to responsiveness of TG sensory neurons to formalin.

Together, cellular experiments reveal that directed expression of TRPV4 is sufficient to render an otherwise minimally responsive cell formalin-responsive, and that the primary sensory neurons of highest interest in our investigation, TG sensory neurons, can be activated directly by formalin in a TRPV4-dependent manner.

\subsection{TRPV4 and pERK co-expressing TG neurons innervate the whiskerpad skin}

Based on these insights, we returned to the TG of control- and formalin-injected mice. First, our immunostaining analysis revealed TRPV4 to be expressed in both epidermal keratinocytes and whiskerpad skin nerve fibers (Fig. 5A-C). Using trigeminal ganglia sampled 5 minutes after whiskerpad injections, we combined co-immunolabeling of TRPV4 and phosphorylated ERK with neural tracing from the whiskerpad skin (Fig. 5D and Table 2). Our results are telling in that they demonstrate a greater number of phosphorylated ERKimmunoreactive neurons in the population of TRPV4-expressing sensory neurons, an increase by $\sim 100 \%$ (Table 2, 5.67\% vs. 10.35\%). Importantly, in TRPV4-expressing neurons that co-label with whiskerpad injected tracer, we found an increase of phosphorylated ERK by $\sim 75 \%$ (11.25\% vs. $18.04 \%$ ). This is an interesting finding when compared to all TG sensory neurons, where phosphorylated ERK expressing neurons tripled from $5.44 \%$ to $15.54 \%$ (Table 2). This means that whiskerpad injections of formalin can possibly activate TG sensory neurons that do not innervate the whiskerpad, which is even more astounding given the time interval between whiskerpad injection of formalin and sampling of the TG, namely 5 minutes. As a measure of the validity of our approach, there was no significant change in abundance of neurons labeled with neural tracer $(6.53 \%$ vs. $6.88 \%$ ) and of neurons showing appreciable TRPV4 expression, evidenced by the fact that TRPV4 could be detected in a straightforward manner by simple 2-step immunolabeling (32.15\% vs. 33.72\%). Together, these findings indicate that TRPV4-expressing TG sensory neurons that innervate the whiskerpad skin become activated to phosphorylate ERK within 5 minutes after formalin injection. This activation is likely to underlie the TRPV4-dependent 
neurally-mediated tonic phase of the trigeminal formalin response that we have characterized here.

\subsection{Co-contribution of TRPA1 and TRPV4 to the trigeminal formalin response}

Based on our findings of a co-contribution of TRPA1 and TRPV4 to the formalin response of TG sensory neurons, we compared nocifensive behavior in pan-null mice for both genes, then applied a TRPV4 inhibitor to Trpal ${ }^{-/-}$mice. Our results demonstrate attenuation of

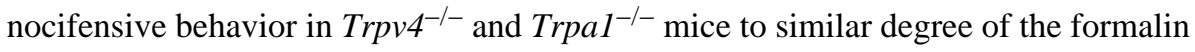
response (Fig. 6A-B). When pre-treated with whiskerpad injection of TRPV4-inhibitor, GSK205 (see Fig. 1G-H), only the tonic phase was significantly attenuated in Trpal ${ }^{-/-}$ mice (Fig. 6A-B). This suggests that both channels co-contribute to the in-vivo effects of formalin, sustaining in particular the tonic phase of the response. We also investigated pERK expression in TG sensory neurons as the intra-cellular down-stream signaling function. We found a significant $\%$ reduction in both null genotypes, indicating that $\mathrm{Ca}^{++}$ influx via either channel can activate MEK-ERK MAP-kinase signaling in TG sensory neurons (Fig. 6C-D). Our in-vivo findings therefore dovetail with the concept of a cocontribution of TRPA1 and TRPV4 to the trigeminal formalin response in-vivo.

\section{Discussion}

In this paper we demonstrate an important role for TRPV4 ion channels in the trigeminal formalin pain response. TRPV4 is contributory to all phases of the trigeminal formalin pain response. Its functional expression in TG sensory neurons is key for the protracted, neurallymediated tonic phase of pain behavior. TRPV4 channels function up-stream of MEK-ERK phosphorylation in whiskerpad-innervating TG sensory neurons to evoke the delayed phase of the pain behavior. In keeping with a key role in transduction of the irritant stimulus, TRPV4 expression in heterologous cellular systems confers robust responsiveness to formalin. TG sensory neurons respond to formalin directly with $\mathrm{Ca}^{++}$influx in a TRPV4dependent manner. These results imply TRPV4 as a novel irritant receptor in the trigeminal system, in addition to the known TRPA1 [3; 24]. Targeting TRPV4 for trigeminal pain disorders might be a rational and possibly gainful new strategy.

With respect to mechanisms of action of formalin on TG sensory neurons, future studies can address these interesting questions: (i) what is the mechanism of the demonstrated cocontribution of TRPV4 and TRPA1 to the trigeminal formalin response $\left(\mathrm{Ca}^{++}\right.$signaling mechanism, channel mechanism, membrane mechanism)? (ii) For TRPV4 channel activation mechanisms by formalin, can direct activation be deconstructed, or is formalin acting on a yet to-be-identified receptor, other membrane protein, or membrane lipidcomplex, which subsequently activates TRPV4?

In regards to trigeminal pain disorders, TRPV4 is likely a molecule-of-interest that regulates the transformation of TG sensory neurons into pain generators. In this process, the $\mathrm{Ca}^{++}$ permeable channel functions up-stream of MEK-ERK MAP-kinase signaling. This is in keeping with another study that we have conducted involving longer-term inflammation of the TMJ using complete Freund's adjuvant [8]. In this model, which lasts almost 2 weeks, we observed longer-term changes of pain-enhancing gene regulation in the TG, dependent 
on TRPV4. MEK-ERK phosphorylation was also found dependent on TRPV4. In the current study, MEK-ERK phosphorylation depends again on $\operatorname{Trpv4}$, but the time dynamics of the formalin model is so rapid - 45 minutes - that gene dysregulation cannot be implied as causative. However, we are struck by the common feature of both studies, namely that TRPV4 is critical for pain behavior, that its expression in TG sensory neurons appears key, and that MEK-ERK signals down-stream of TRPV4 as a critical effector mechanisms in the animals' pain behavior. This means that TRPV4 is now a more validated, bona-fide target for relief of pain [18] in the trigeminal system. This includes headaches, including migraines and tension type headaches, TMJ pain, sinus pain, trigeminal neuropathic pain, trigeminal neuralgia, tooth pain and oro-facial sensory disorders with a pain-equivalent component, e.g. "burning mouth syndrome". The relative contribution of TRPV4 to these pain disorders needs to be established in future studies, which can now be conducted in a more rational manner, based on our results presented here and in our previous study [8]. We note that mechanical hypersensitivity, such as hyperalgesia and allodynia, and inflammationfacilitated pain are a common feature of these disorders. This clinical argument reinvigorates TRPV4 an appealing target molecule. Beyond classic trigeminal pain disorders, TRPV4 might be functional in trigeminal irritation disorders evoked by airborne exposures of trigeminally-innervated external barriers (e.g. cornea and conjunctiva of the eye; mucous membranes of the nasal cavity, nasopharynx, sinuses, oral cavity and pharynx) to formalin and related electrophilic irritants [19].

Specific inhibition of TRPV4 can therefore be a novel therapeutic principle for trigeminal pain as well as irritation disorders. Especially for the latter, topical application of TRPV4 inhibitors might be suitable and effective remedies.

\section{Supplementary Material}

Refer to Web version on PubMed Central for supplementary material.

\section{Acknowledgments}

This study was supported by NIH grants DE018549 (WL), F33DE024668 (YC), DE19440 (FW), and NS48602 and NS42595 (RWG), support from the Duke Institute for Brain Science (DIBS) to WL and FW, a Leon Goldberg Fellowship (Nicholas School for the Environment, Duke University) to YC, and a Minority Supplement DE018549S to CM. We thank Drs. Sidney A. Simon, Ru-rong Ji and Jörg Grandl (Duke University) for careful proof-reading of the manuscript.

\section{References}

1. Alessandri-Haber N, Yeh JJ, Boyd AE, Parada CA, Chen X, Reichling DB, Levine JD. Hypotonicity induces TRPV4-mediated nociception in rat. Neuron. 2003; 39:497-511. [PubMed: 12895423]

2. Alvarez DF, King JA, Weber D, Addison E, Liedtke W, Townsley MI. Transient receptor potential vanilloid 4-mediated disruption of the alveolar septal barrier: a novel mechanism of acute lung injury. Circ Res. 2006; 99:988-95. [PubMed: 17008604]

3. Bessac BF, Sivula M, von Hehn CA, Caceres AI, Escalera J, Jordt SE. Transient receptor potential ankyrin 1 antagonists block the noxious effects of toxic industrial isocyanates and tear gases. FASEB J. 2009; 23:1102-14. [PubMed: 19036859]

4. Birder L, Kullmann FA, Lee H, Barrick S, de Groat W, Kanai A, Caterina M. Activation of urothelial transient receptor potential vanilloid 4 by 4 alpha-phorbol 12,13-didecanoate contributes 
to altered bladder reflexes in the rat. J Pharmacol Exp Ther. 2007; 323:227-35. [PubMed: 17636010]

5. Borsani E, Albertini R, Labanca M, Lonati C, Rezzani R, Rodella LF. Peripheral purinergic receptor modulation influences the trigeminal ganglia nitroxidergic system in an experimental murine model of inflammatory orofacial pain. J Neurosci Res. 2010; 88:2715-26. [PubMed: 20648657]

6. Campagnola L, Wang H, Zylka MJ. Fiber-coupled light-emitting diode for localized photostimulation of neurons expressing channelrhodopsin-2. J Neurosci Methods. 2008; 169:27-33. [PubMed: 18187202]

7. Chen J, Joshi SK, DiDomenico S, Perner RJ, Mikusa JP, Gauvin DM, Segreti JA, Han P, Zhang XF, Niforatos W, Bianchi BR, Baker SJ, Zhong C, Simler GH, McDonald HA, Schmidt RG, McGaraughty SP, Chu KL, Faltynek CR, Kort ME, Reilly RM, Kym PR. Selective blockade of TRPA1 channel attenuates pathological pain without altering noxious cold sensation or body temperature regulation. Pain. 2011; 152:1165-72. [PubMed: 21402443]

8. Chen Y, Williams SH, McNulty AL, Hong JH, Lee SH, Rothfusz NE, Parekh PK, Moore C, Gereau RWt, Taylor AB, Wang F, Guilak F, Liedtke W. Temporomandibular joint pain: a critical role for Trpv4 in the trigeminal ganglion. Pain. 2013; 154:1295-304. [PubMed: 23726674]

9. Dubuisson D, Dennis SG. The formalin test: a quantitative study of the analgesic effects of morphine, meperidine, and brain stem stimulation in rats and cats. Pain. 1977; 4:161-74. [PubMed: 564014]

10. Everaerts W, Zhen X, Ghosh D, Vriens J, Gevaert T, Gilbert JP, Hayward NJ, McNamara CR, Xue F, Moran MM, Strassmaier T, Uykal E, Owsianik G, Vennekens R, De Ridder D, Nilius B, Fanger CM, Voets T. Inhibition of the cation channel TRPV4 improves bladder function in mice and rats with cyclophosphamide-induced cystitis. Proc Natl Acad Sci U S A. 2010; 107:19084-9. [PubMed: 20956320]

11. Fischer M, Carli G, Raboisson P, Reeh P. The interphase of the formalin test. Pain. 2013; 155:51121. [PubMed: 24291649]

12. Groot-Kormelink PJ, Fawcett L, Wright PD, Gosling M, Kent TC. Quantitative GPCR and ion channel transcriptomics in primary alveolar macrophages and macrophage surrogates. BMC Immunol. 2012; 13:57. [PubMed: 23102269]

13. Hamanaka K, Jian MY, Townsley MI, King JA, Liedtke W, Weber DS, Eyal FG, Clapp MM, Parker JC. TRPV4 channels augment macrophage activation and ventilator-induced lung injury. Am J Physiol. 2010; 299:L353-62.

14. Ji RR, Baba H, Brenner GJ, Woolf CJ. Nociceptive-specific activation of ERK in spinal neurons contributes to pain hypersensitivity. Nat Neurosci. 1999; 2:1114-9. [PubMed: 10570489]

15. Ji RR, Samad TA, Jin SX, Schmoll R, Woolf CJ. p38 MAPK activation by NGF in primary sensory neurons after inflammation increases TRPV1 levels and maintains heat hyperalgesia. Neuron. 2002; 36:57-68. [PubMed: 12367506]

16. Karim F, Hu HJ, Adwanikar H, Kaplan D, Gereau RWt. Impaired inflammatory pain and thermal hyperalgesia in mice expressing neuron-specific dominant negative mitogen activated protein kinase kinase (MEK). Mol Pain. 2006; 2:2. [PubMed: 16412244]

17. Karim F, Wang CC, Gereau RWt. Metabotropic glutamate receptor subtypes 1 and 5 are activators of extracellular signal-regulated kinase signaling required for inflammatory pain in mice. $\mathrm{J}$ Neurosci. 2001; 21:3771-9. [PubMed: 11356865]

18. Levine JD, Alessandri-Haber N. TRP channels: Targets for the relief of pain. Biochim Biophys Acta. 2007; 1772:989-1003. [PubMed: 17321113]

19. Li J, Kanju P, Patterson M, Chew WL, Cho SH, Gilmour I, Oliver T, Yasuda R, Ghio A, Simon SA, Liedtke W. TRPV4-mediated calcium influx into human bronchial epithelia upon exposure to diesel exhaust particles. Environ Health Perspect. 2011; 119:784-93. [PubMed: 21245013]

20. Liedtke W, Choe Y, Marti-Renom MA, Bell AM, Denis CS, Sali A, Hudspeth AJ, Friedman JM, Heller S. Vanilloid receptor-related osmotically activated channel (VR-OAC), a candidate vertebrate osmoreceptor. Cell. 2000; 103:525-35. [PubMed: 11081638]

21. Liedtke W, Tobin DM, Bargmann CI, Friedman JM. Mammalian TRPV4 (VR-OAC) directs behavioral responses to osmotic and mechanical stimuli in Caenorhabditis elegans. Proc Natl Acad Sci U S A. 2003; 100(Suppl 2):14531-6. [PubMed: 14581619] 
22. Luccarini P, Childeric A, Gaydier AM, Voisin D, Dallel R. The orofacial formalin test in the mouse: a behavioral model for studying physiology and modulation of trigeminal nociception. $\mathrm{J}$ Pain. 2006; 7:908-14. [PubMed: 17157777]

23. Macpherson LJ, Xiao B, Kwan KY, Petrus MJ, Dubin AE, Hwang S, Cravatt B, Corey DP, Patapoutian A. An ion channel essential for sensing chemical damage. J Neurosci. 2007; 27:11412-5. [PubMed: 17942735]

24. McNamara CR, Mandel-Brehm J, Bautista DM, Siemens J, Deranian KL, Zhao M, Hayward NJ, Chong JA, Julius D, Moran MM, Fanger CM. TRPA1 mediates formalin-induced pain. Proc Natl Acad Sci U S A. 2007; 104:13525-30. [PubMed: 17686976]

25. Mendell MJ. Indoor residential chemical emissions as risk factors for respiratory and allergic effects in children: a review. Indoor Air. 2007; 17:259-77. [PubMed: 17661923]

26. Moore C, Cevikbas F, Pasolli HA, Chen Y, Kong W, Kempkes C, Parekh P, Lee SH, Kontchou NA, Yeh I, Jokerst NM, Fuchs E, Steinhoff M, Liedtke WB. UVB radiation generates sunburn pain and affects skin by activating epidermal TRPV4 ion channels and triggering endothelin-1 signaling. Proc Natl Acad Sci U S A. 2013; 110:E3225-34. [PubMed: 23929777]

27. O’Neil RG, Heller S. The mechanosensitive nature of TRPV channels. Pflugers Arch. 2005; 451:193-203. [PubMed: 15909178]

28. Phan MN, Leddy HA, Votta BJ, Kumar S, Levy DS, Lipshutz DB, Lee SH, Liedtke W, Guilak F. Functional characterization of TRPV4 as an osmotically sensitive ion channel in porcine articular chondrocytes. Arthritis Rheum. 2009; 60:3028-37. [PubMed: 19790068]

29. Ritchie IM, Lehnen RG. Formaldehyde-related health complaints of residents living in mobile and conventional homes. Am J Public Health. 1987; 77:323-8. [PubMed: 3812839]

30. Schwartz ES, La JH, Scheff NN, Davis BM, Albers KM, Gebhart GF. TRPV1 and TRPA1 antagonists prevent the transition of acute to chronic inflammation and pain in chronic pancreatitis. J Neurosci. 2013; 33:5603-11. [PubMed: 23536075]

31. Shalin SC, Zirrgiebel U, Honsa KJ, Julien JP, Miller FD, Kaplan DR, Sweatt JD. Neuronal MEK is important for normal fear conditioning in mice. J Neurosci Res. 2004; 75:760-70. [PubMed: 14994337]

32. Shi X, Li X, Clark JD. Formalin injection causes a coordinated spinal cord CO/NO-cGMP signaling system response. Mol Pain. 2005; 1:33. [PubMed: 16297238]

33. Shimada SG, LaMotte RH. Behavioral differentiation between itch and pain in mouse. Pain. 2008; 139:681-7. [PubMed: 18789837]

34. Tang Q, Svensson CI, Fitzsimmons B, Webb M, Yaksh TL, Hua XY. Inhibition of spinal constitutive NOS-2 by $1400 \mathrm{~W}$ attenuates tissue injury and inflammation-induced hyperalgesia and spinal p38 activation. Eur J Neurosci. 2007; 25:2964-72. [PubMed: 17561811]

35. Tjolsen A, Berge OG, Hunskaar S, Rosland JH, Hole K. The formalin test: an evaluation of the method. Pain. 1992; 51:5-17. [PubMed: 1454405]

36. Vriens J, Owsianik G, Fisslthaler B, Suzuki M, Janssens A, Voets T, Morisseau C, Hammock BD, Fleming I, Busse R, Nilius B. Modulation of the Ca2 permeable cation channel TRPV4 by cytochrome P450 epoxygenases in vascular endothelium. Circ Res. 2005; 97:908-15. [PubMed: 16179585]

37. Vriens J, Owsianik G, Janssens A, Voets T, Nilius B. Determinants of 4 alpha-phorbol sensitivity in transmembrane domains 3 and 4 of the cation channel TRPV4. J Biol Chem. 2007; 282:12796803. [PubMed: 17341586]

38. Walker K, Fox AJ, Urban LA. Animal models for pain research. Mol Med Today. 1999; 5:319-21. [PubMed: 10498437]

39. Wei H, Saarnilehto M, Falck L, Viisanen H, Lasierra M, Koivisto A, Pertovaara A. Spinal transient receptor potential ankyrin 1 channel induces mechanical hypersensitivity, increases cutaneous blood flow, and mediates the pronociceptive action of dynorphin A. J Physiol Pharmacol. 2013; 64:331-40. [PubMed: 23959730]

40. Woolf CJ. Evidence for a central component of post-injury pain hypersensitivity. Nature. 1983; 306:686-8. [PubMed: 6656869]

41. Ye L, Kleiner S, Wu J, Sah R, Gupta RK, Banks AS, Cohen P, Khandekar MJ, Bostrom P, Mepani RJ, Laznik D, Kamenecka TM, Song X, Liedtke W, Mootha VK, Puigserver P, Griffin PR, 
Clapham DE, Spiegelman BM. TRPV4 is a regulator of adipose oxidative metabolism, inflammation, and energy homeostasis. Cell. 2012; 151:96-110. [PubMed: 23021218] 


\section{Summary}

Our study demonstrates that formalin-evoked trigeminal pain behavior depends on TRPV4 calcium-permeable channels, also on MEK-ERK signaling in trigeminal ganglion neurons. 


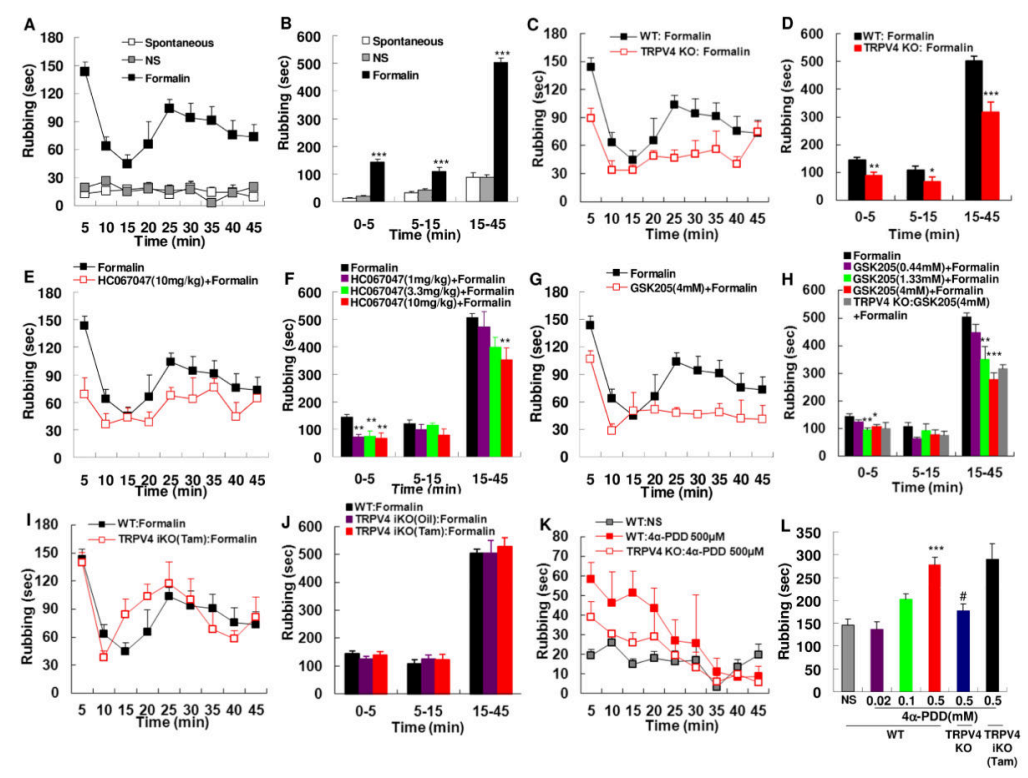

Fig. 1.

Trpv4 in trigeminal ganglion (TG) sensory neurons is essential for formalin evoked irritant pain. (A) Time course of the face-rubbing activity observed in naive mice and in mice after subcutaneous injection of normal saline (NS) or formalin $(4 \%)$ into the whiskerpad. Time that mice spent rubbing is plotted for each 5-min block over $45 \mathrm{~min}$. (B) Quantification of the formalin response binned into different phases: acute phase (0-5 $\mathrm{min})$, interphase (5-15 $\mathrm{min})$, and tonic phase (15-45 $\mathrm{min})(* * * P<0.001 \mathrm{vs} \mathrm{NS})$. Significant attenuation of irritant pain induced by formalin was observed in mice lacking $\operatorname{Trp} v 4(\mathrm{C}-\mathrm{D} ; * P<0.05, * * P<0.01$ and $* * * P<0.001$ vs WT: Formalin), systemically pretreated (i.p.) or subcutaneously (s.c.) pretreated with the TRPV4 inhibitor HC067047 (E-F; ** $P<0.01$ vs Formalin) or GSK205 (G-H; $* P<0.05, * * P<0.01$ and $* * * P<0.001$ vs Formalin; the absence of off-target effects of GSK205 is demonstrated in $\operatorname{Trp} v 4^{-/-}$mice), but not in mice with inducible $\operatorname{Tr} p v 4$ deletions in keratinocytes (I-J). In addition, mice pretreated with the selective inhibitors showed dosedependent reduction of rubbing activity for the tonic phase $(\mathrm{F}$ and $\mathrm{H})$. Animals injected with the TRPV4 selective agonist, 4a-PDD, displayed significant rubbing behavior of single phase in a dose-dependent manner that was absent in $\operatorname{Trp} v 4^{-/-}$mice, but unaffected by ablating Trpv4 in keratinocytes (K-L; *** $P<0.001$ vs NS and ${ }^{\#} P<0.05$ vs WT: $0.5 \mathrm{mM} 4 \mathrm{a}-$ PDD). N=5-9/group, and one-way ANOVA with Tukey post-hoc test was used for statistic analyses. 

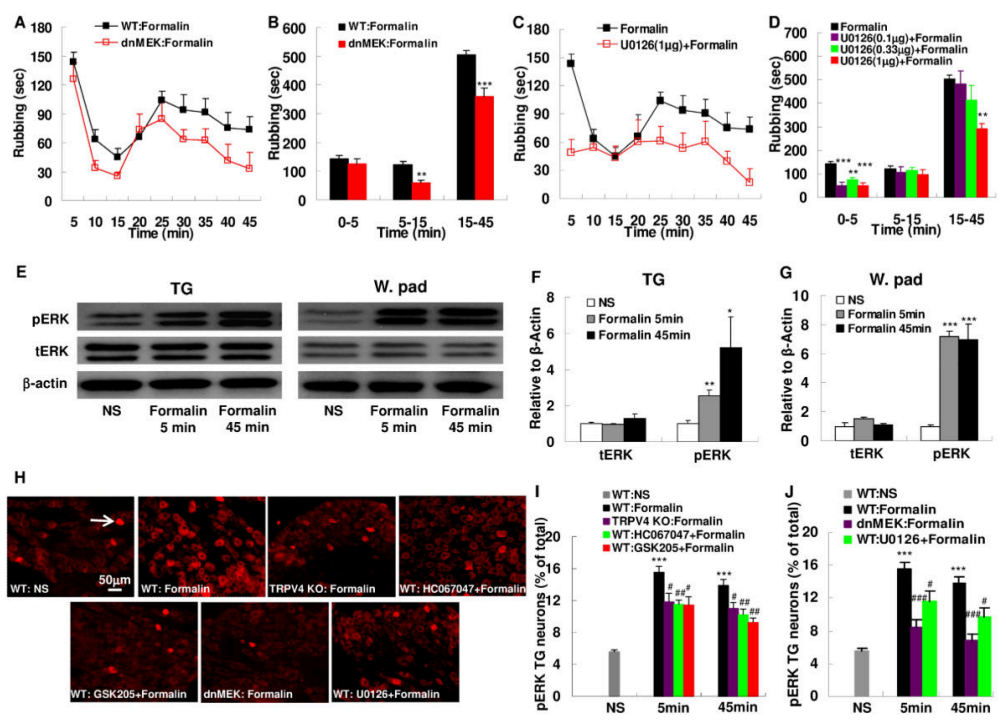

Fig. 2.

Extracellular signal-related kinase (ERK) signaling downstream of TRPV4 is critical for formalin evoked irritant pain. Reduced tonic phase of irritant pain was observed in the dominant negative mitogen-activated protein kinase kinase (dnMEK) mice (A-B; $n=7-9$ / group, $* * P<0.01$ and $* * * P<0.001$ vs WT: Formalin). Different from the dnMEK mutant mice, animals subcutaneously pretreated with the selective MEK inhibitor U0126 not only showed reduction of the tonic phase of pain, but also of the acute phase $(C-D ; n=5-9$ /group, $* * P<0.01$ and $* * * P<0.001$ vs Formalin). (E-J) Increase of phospho-ERK (pERK)

expressing TG neurons in response to formalin depends on Trpv4. Micrographs show pERK and total-ERK (tERK) expression in the TG and whiskerpad skin homogenates as revealed by Western blot (E). Right bar graphs depict quantitation. Note early and robust increase of pERK expression and unchanged tERK expression in the TG and whiskerpad (W.pad) skin after formalin ( $\mathrm{F}-\mathrm{G} ; \mathrm{n}=5$ /group, $* P<0.05$, $* * P<0.01$ and $* * * P<0.001$ vs NS). (H-I) further show that the increase of pERK in TG is restricted predominantly to neurons and significantly inhibited in mice lacking Trpv4 or pretreated with the TRPV4 selective inhibitors (n=4-5/group, *** $P<0.001$ vs NS, ${ }^{\#} P<0.05$ and ${ }^{\# \#} P<0.01$ vs WT: Formalin). (H and $\mathrm{J}$ ) note an increase of pERK is inhibited in dnMEK mutant mice and in mice pretreated with the MEK selective inhibitor U0126, as expected ( $\mathrm{n}=4-5 /$ group, ${ }^{\#} P<0.05$, and ${ }^{\# \# \#} P<0.001$ vs WT: Formalin). One-way ANOVA with Tukey post-hoc test was used for $\mathrm{B}$ and $\mathrm{D}$, and two-tail $t$-test was used for $\mathrm{F}, \mathrm{G}, \mathrm{I}$ and $\mathrm{J}$. 
A

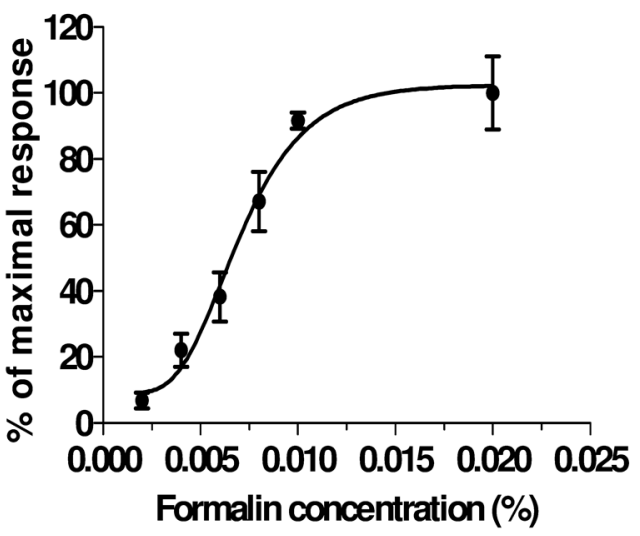

C

rTRPV4: Formalin

— rTRPV4: GSK205(10 $\mu \mathrm{M})$

+ Formalin

- GFP: Formalin

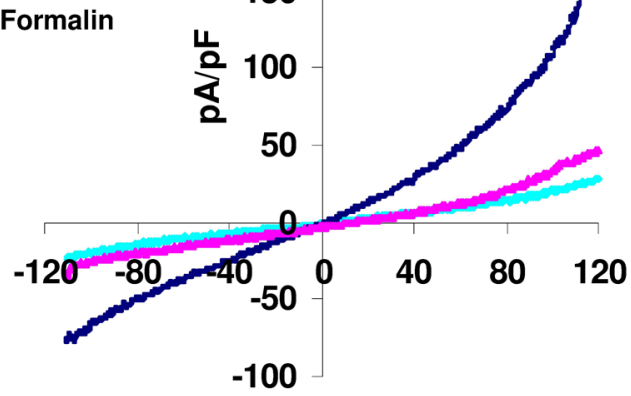

Fig. 3.
B

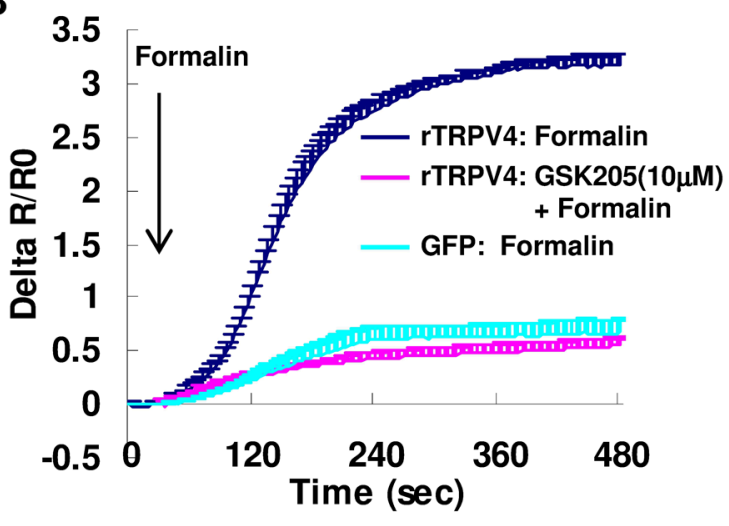

D

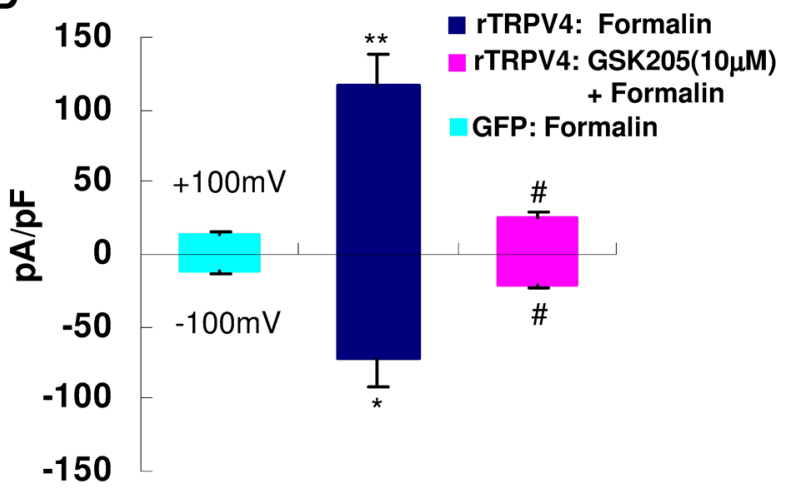

Formalin activates heterologously expressed TRPV4. (A) Concentration-dependent curve of $\mathrm{Ca}^{++}$influx induced by formalin in N2a cells transfected with rTRPV4 (64-312 cells/ concentration). (B) $\mathrm{Ca}^{++}$responses caused by formalin $(0.01 \%)$ were reversed by pretreatment of the TRPV4 selective inhibitor GSK205 to a level equivalent to control cells transfected with green fluorescent protein (GFP, 89-133 cells/group). (C) Inhibition of formalin $(0.01 \%)$-evoked currents by GSK205 in N2a cells transfected with rTRPV4. (D) Mean current density measured at +100 and $-100 \mathrm{mV}$ in response to formalin $(0.01 \%)$ and co-application of GSK205 (6-12 cells/group, ${ }^{* *} P<0.01$ vs GFP: Formalin and ${ }^{\#} P<0.05$ vs rTRPV4: Formalin, Two-tail $t$-test). 
A

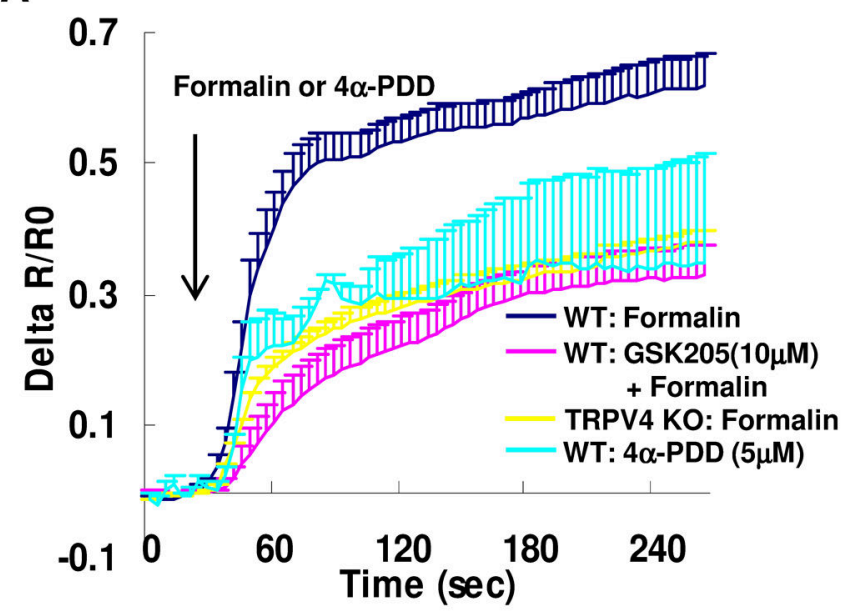

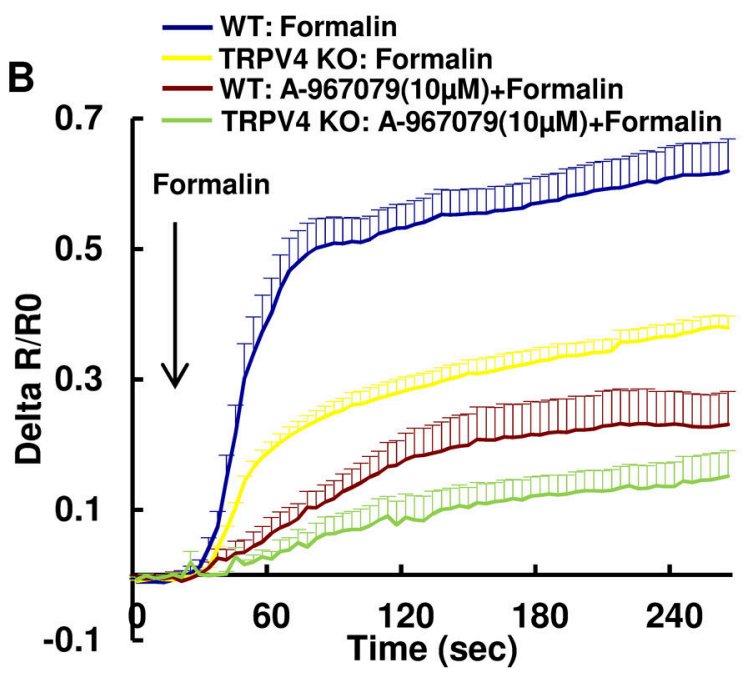

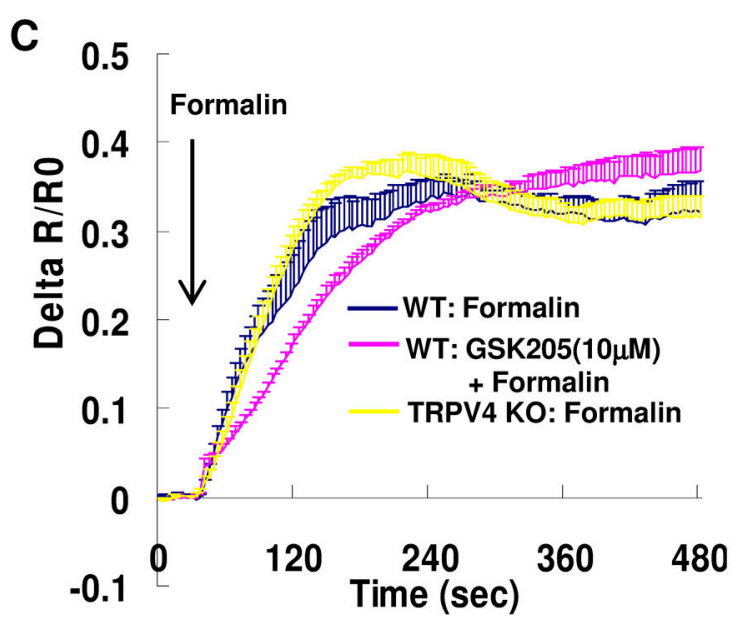

Fig. 4.

$\mathrm{Ca}^{++}$influx caused by formalin in TG neurons is TRPV4 dependent. (A) Formalin (0.01\%)evoked $\mathrm{Ca}^{++}$influx was attenuated in the presence of TRPV4-selective inhibitor GSK205 in cultured TG neurons, also in TG neurons from $\operatorname{Trp} v 4^{-/-}$mice. In addition, $\mathrm{Ca}^{++}$influx was evoked by the TRPV4 selective agonist 4a-PDD (166-517 cells/group). (B) A-967079, a specific TRPA1 inhibitor, led to an attenuated $\mathrm{Ca}^{++}$signal in WT TG neurons, and to further reduction in neurons from $\operatorname{Trpv} 4^{-/-}$. (C) Formalin (0.01\%)-evoked $\mathrm{Ca}^{++}$signaling was not affected by GSK205 in cultured keratinocytes and remained completely unaffected in keratinocytes derived from $\operatorname{Trp} v 4^{-/-}$mice (170-457 cells/group). 
A

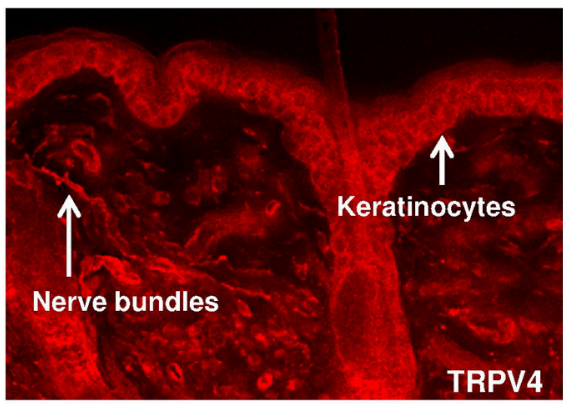

TRPV4
B

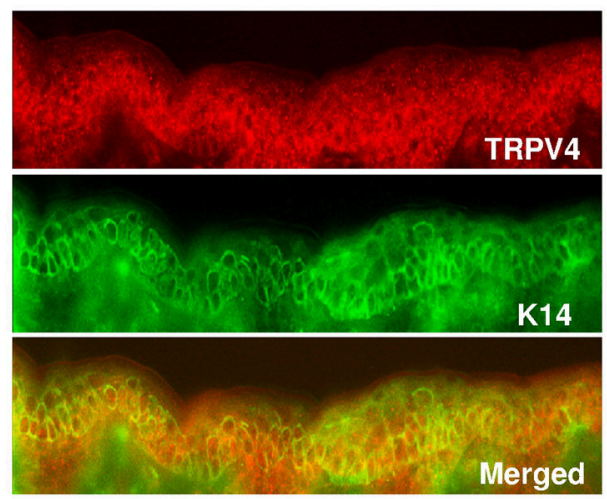

C
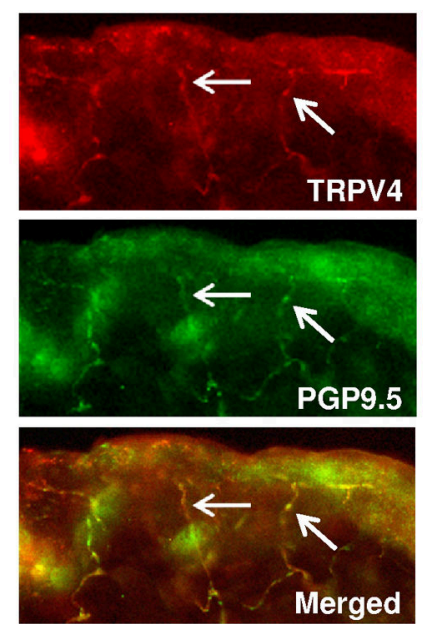

D

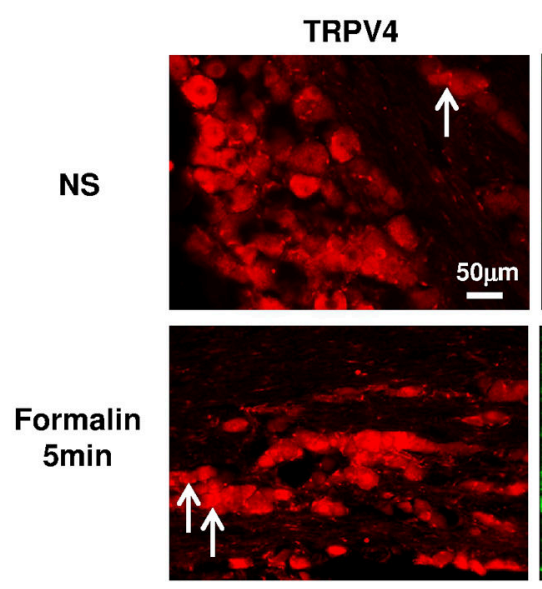

PERK
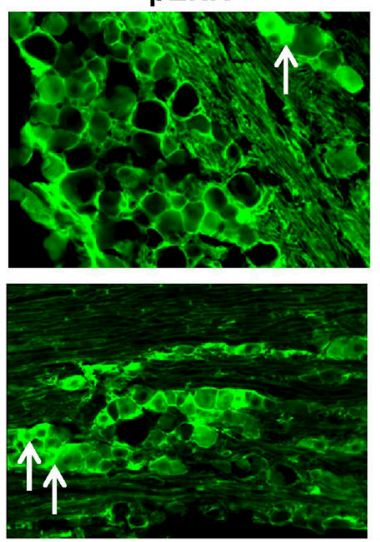

FB
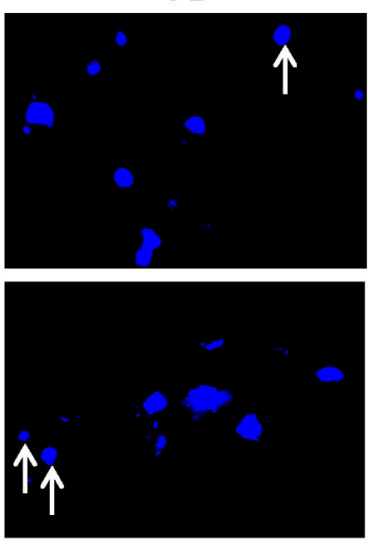
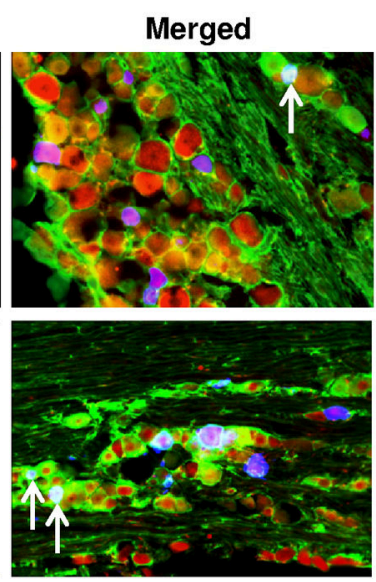

Fig. 5.

TRPV4 and pERK co-expressing TG neurons innervate the whiskerpad skin. (A) Immunostaining revealed TRPV4 expression in epidermal keratinocytes and whiskerpad skin nerve fibers, as demonstrated by co-labeling with the specific keratinocyte marker K14 in WT mice (B) and peripheral nerve fiber marker PGP9.5 in (Trpv4lox/lox X K14-Cre$\mathrm{ER}^{\mathrm{tam}}$ ) keratinocyte-specific and inducible Trpv4 knockout mice (C) respectively. (D) TRPV4 co-expresses with pERK in TG neurons that innervate the whiskerpad, as identified with fast blue (FB) tracing that is originating from the whiskerpad. 

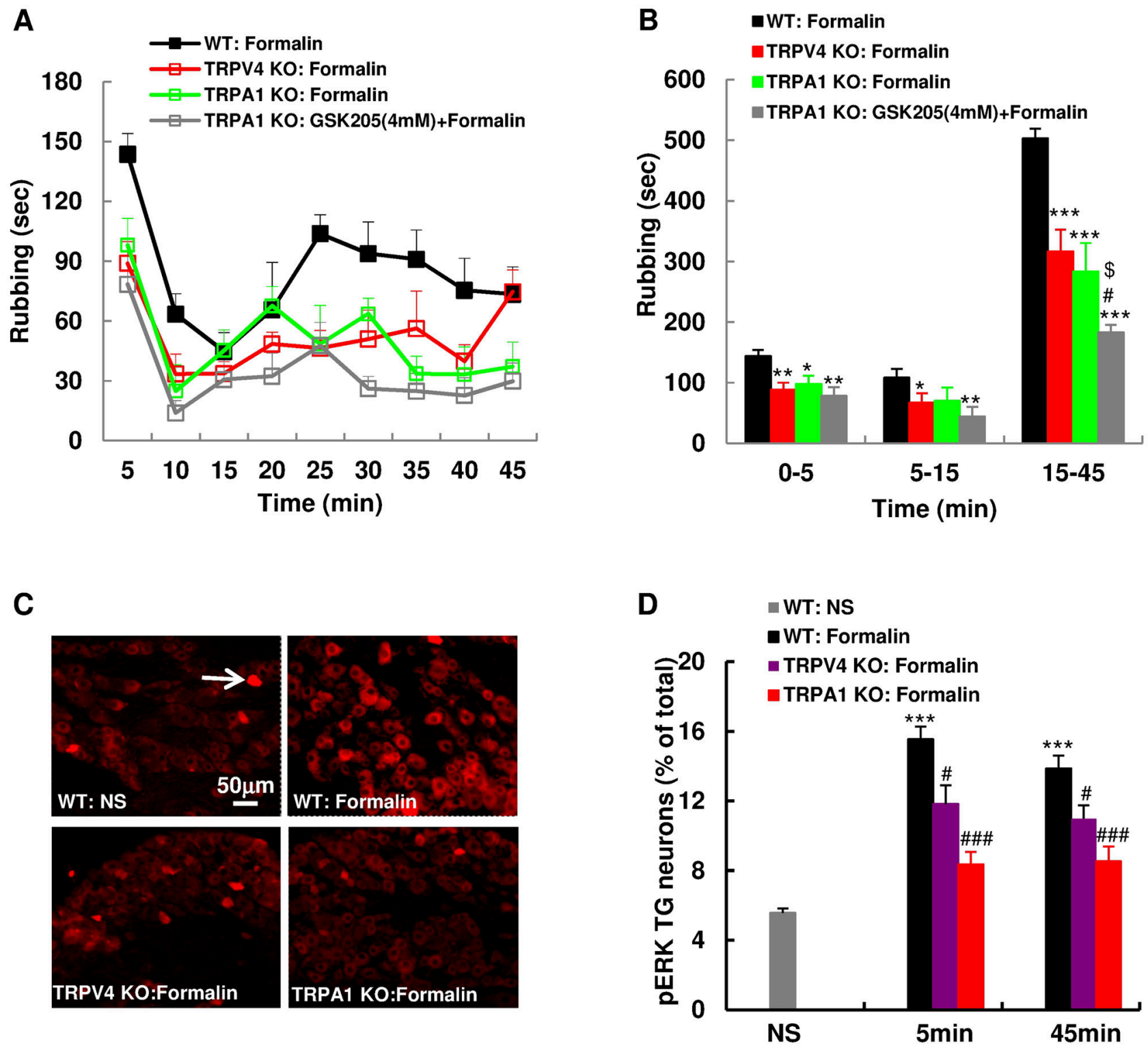

Fig. 6.

Co-contribution of TRPA1 and TRPV4 to the trigeminal formalin response. (A-B)

Significant attenuation of irritant pain induced by formalin was observed in mice lacking Trpal, and this attenuation was further reduced by subcutaneous (s.c.) pretreatment with the TRPV4 inhibitor GSK205 for the tonic phase $(* * P<0.01$ and $* * * P<0.001$ vs WT:

Formalin, ${ }^{\$} P<0.05$ vs TRPA1 KO: Formalin, and ${ }^{\#} P<0.01$ vs TRPV4 KO: Formalin; n=5-9/ group). (C-D) Increase of pERK in TG neurons caused by formalin injection is significantly reduced in mice lacking Trpal ( $\mathrm{n}=4-5 /$ group, $* * * P<0.001$ vs WT: NS, ${ }^{\#} P<0.05$

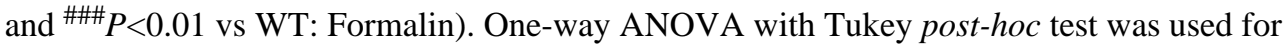
$\mathrm{A}$ and $\mathrm{B}$, and two-tail $t$-test was used for $\mathrm{C}$ and $\mathrm{D}$. 


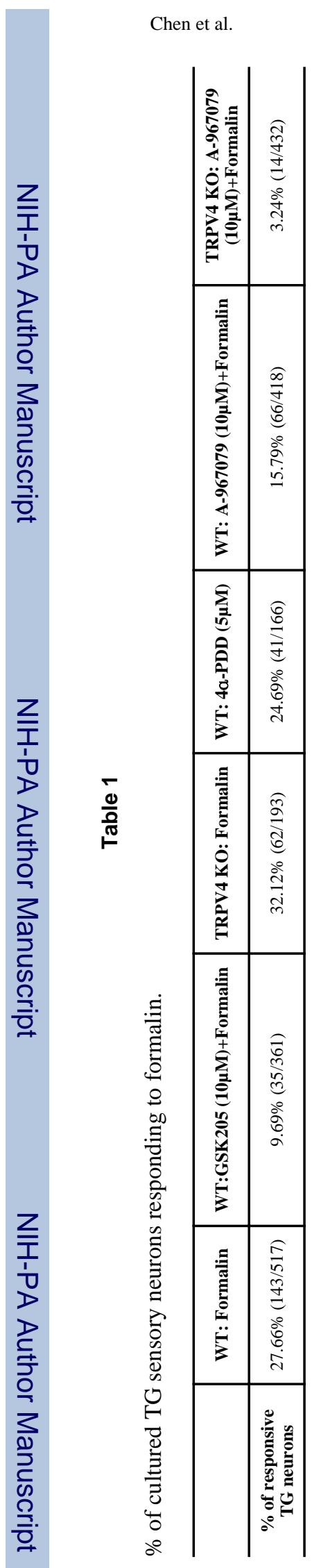

Page 23

Pain. Author manuscript; available in PMC 2015 December 01. 
峁

巳্ّ

๑

¿ 0

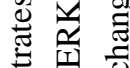

苞䎡

寻守

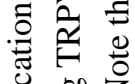

近

壳芯

..

㽦 总

눙

$03>$

훙

品

$\Xi$ :

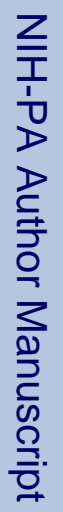

吾

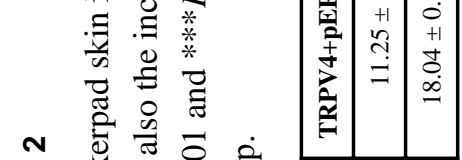

음

औิ

$\exists * \frac{50}{8}$

$\doteq$ ‥

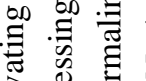

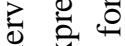

छ

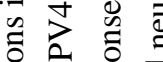

言哇造

ठ․

U

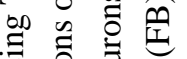

के छ

范

শ

8 bo 3

㻤

㱐

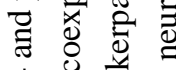

支记

金跔

苟䨔

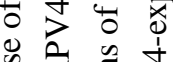

के

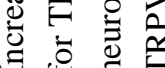

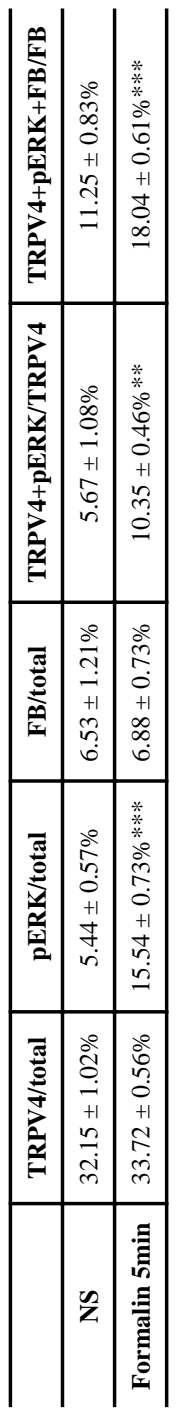

Pain. Author manuscript; available in PMC 2015 December 01. 